\title{
'Florida Slobolt M68': A Spring Celery Cultivar for Florida
}

\author{
E.A. Wolf \\ Everglades Research and Education Center, Institute of Food and Agricultural \\ Sciences, University of Florida, 3200 Palm Beach Road, Belle Glade, \\ FL 33430-8003
}

J.M. White ${ }^{2}$

Central Florida Research and Education Center, Institute of Food and Agricultural Sciences, University of Florida, Sanford, FL 32771-9608

\section{R.S. Stubblefield ${ }^{3}$ and B. Scully ${ }^{4}$ \\ Everglades Research and Education Center, Institute of Food and Agricultural Sciences, University of Florida, 3200 Palm Beach Road, Belle Glade, \\ FL 33430-8003}

Additional index words. Apium graveolens, slow bolting, early blight resistance, pedigree breeding

Celery (Apium graveolens L.) is grown as an annual leafy vegetable crop with a biennial reproductive cycle. In southern Florida, celery production is year-round: seeding begins in June and continues through January, and harvest is from November to the middle of the following June. The celery production season is divided into four production periods: late autumn, winter, spring bolting, and spring postbolting. Each production period requires separately adapted cultivars. The celery crop harvested during the spring bolting season is seeded in November and December, transplanted to the field in February and March, and harvested in April and early May, when the weather is cool and dry and daylength is increasing.

A major constraint in the April to May harvest period is premature bolting induced by prolonged suboptimal temperatures that vernalize the crop early in the production cycle. Premature bolting results in seed-stem elongation, which, combined with other changes in horticultural quality, can force an early harvest and result in lower yields, lower grade sizes, or stalk rejection. Floral induction and associated regenerative processes result mainly from vernalization experienced in December and January. In contrast, warmer weather patterns and more frequent rainfall in April and

Received for publication 28 Sept. 1992. Accepted for publication $8 \mathrm{Feb}$. 1993. Florida Agricultural Experiment Station journal series no. R-02649. This research was supported in part by the Florida Celery Exchange. We extend our thanks and appreciation to A. Duda and Sons, D.D. Division Farms, South Bay Growers, and the Florida Celery Exchange. The cost of publishing this paper was defrayed in part by the payment of page charges. Under postal regulations, this paper therefore must be hereby marked advertisement solely to indicate this fact.

'Professor Emeritus.

${ }^{2}$ Associate Professor and Assistant Center Director. ${ }^{3}$ Senior Biological Scientist.

${ }^{4}$ Assistant Professor; to whom reprint requests should be addressed.
May induce occasional disease epiphytotics of early blight (Cercospora apii Fres.) on maturing celery. Standard Florida cultivars, such as 'Florida 683' and 'Florida 2-14', bolt prematurely in extended cool winters and are susceptible to early blight. 'Florida Slobolt M68', tested in Florida as M68-29-5M, was selected for improved adaptation and horticultural quality, with primary emphasis on resistance to premature bolting and early blight. The cultivar name denotes place of origin, the main improvement, and the source population.

\section{Origin}

'Florida Slobolt M68' was developed by a breeding method that included two crosses followed by a single-plant selection (Fig. 1). In each generation, 12-week-old seedlings were vernalized artificially at $7 \mathrm{C}$ for 5 weeks, transplanted to the field in mid-February, and grown without fungicide protection under severe early

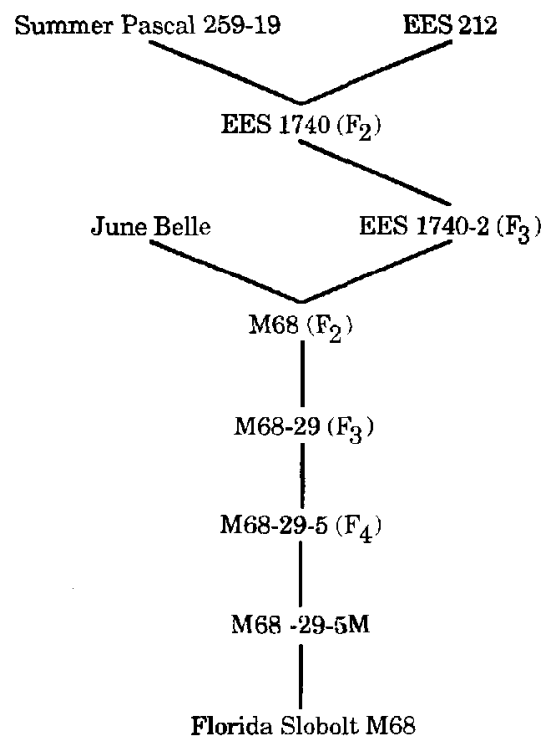

Fig. 1. 'Florida Slobolt M68' pedigree. blight pressure. Bolting and early blight-resistant plants were selected in April for yield and horticultural quality. The first $\mathrm{F}_{2}$ population was derived from a cross between 'Summer Pascal 259-19', a slow-bolting cultivar, and EES 212, an early blight-resistant breeding line. EES212 was selected from breeding line B56-136, which was the source population for 'Emerald' (Wolf, 1958). From this cross, a superior $\mathrm{F}_{3}$ line (EES 1740-2) was identified, selected, and crossed as a male to 'June Belle' (Wolf, 1970b), with the $\mathrm{F}_{2}$ population denoted as M68. In the $\mathrm{F}_{4}$ population, M68-29-5 was selected, massed in the $\mathrm{F}_{5}$ population, and tested as M68-29-5M for 3 years before being released as 'Florida Slobolt M68'.

\section{Description}

'Florida Slobolt M68' is a medium-green Utah-type [U.S. Dept. of Agriculture (USDA), 1981] cultivar adapted to the Florida production period when celery is harvested in April and early May. It is a vigorous midseason cultivar that matures in 80 to 90 days after being transplanted and is usually a few days earlier than 'June Belle' (Wolf, 1970a) and 'Florida 2-14'. Plants range in height from 79 to $84 \mathrm{~cm}$, with an average height of $82 \mathrm{~cm}$ when grown on a 60 -cm-row spacing with 17 to $20 \mathrm{~cm}$ between plants in the row. Plants are 5 to $15 \mathrm{~cm}$ shorter in wider-spaced cropping systems or in border rows. Generally, 'Florida Slobolt M68' is 5.0 to $8.0 \mathrm{~cm}$ taller than 'June Belle', 6.0 to $10.0 \mathrm{~cm}$ taller than 'Florida 683' (Wolf, 1964), and $\approx 2.0 \mathrm{~cm}$ taller than 'Florida 2-14'. Trimmed and stripped mature stalks in the 2-, 21/2-, 3-, and 4-dozen-sized crates have 10 to 15 outer petioles, all $>40 \mathrm{~cm}$ long when measured from leaf tip to petiole base. The inner petioles range from one to three, with $\approx 75 \%$ of these $<40 \mathrm{~cm}$. Stalk conformation is mostly compact to slightly open, with few or no suckers; stalk shape is cylindrical to slightly flared, like that of 'Summer Pascal'. Heart formation is similar to that of 'Summer Pascal', but fuller. Etiolated heart leaves average $12.8 \mathrm{~cm}$ in length and 4 to $8 \mathrm{~mm}$ in crosssectional thickness.

Petiole length, as measured from the petiole base to the first node, averages $25.8 \mathrm{~cm}$ and ranges from 19.4 to $32.3 \mathrm{~cm}$. Petiole width, measured at the midpoint between petiole wing and the first node (USDA, 198 1), ranges up to $23.0 \mathrm{~mm}$, and cross-sectional thickness at the same point averages $10.2 \mathrm{~mm}$ and ranges from 8.0 to $13.0 \mathrm{~mm}$. Cross-sectional petiole shape is deep to moderately cupped, and petiole leaf color is medium green, glossy, and resembles that of 'Florida 683'. Petioles are moderately ribbed. The basal portion of the petiole is $>5.0$ $\mathrm{cm}$ wide and attaches from $120^{\circ}$ to $180^{\circ}$ around the stem. Distance from the wing to the petiole base is usually $5.0 \mathrm{~cm}$, but ranges up to $8.0 \mathrm{~cm}$. This structure is very cupped, flared, and partially blanched.

'Florida Slobolt M68,' outyielded 'June Belle' and 'Florida 2-14' in Florida's main production regions (Table 1). 'Florida Slobolt M68' yields were higher in Zellwood, an area north of the Everglades agricultural area that 
Table 1. Yield comparison between 'Florida Slobolt M68' and the standard cultivars grown on nine test sites in southern Florida.

\begin{tabular}{llr}
\hline & \multicolumn{2}{c}{ Yield \pm se (crates/hectare) } \\
\cline { 2 - 3 } Cultivar & Everglades $^{\mathrm{z}}$ & Zellwood \\
\hline Florida Slobolt M68 & $2439 \pm 388$ & $2372 \pm 158$ \\
June Belle & $1836 \pm 1001$ & $1334 \pm 716$ \\
Florida 2-14 & $1663 \pm 946$ & $729 \pm 576$ \\
\hline${ }^{2}$ Results based on nine site-year environments.
\end{tabular}

${ }^{y}$ Results based on two site-year environments.

usually has chilling sufficient to stimulate bolting. In the Everglades, low temperatures vernalized the crop in only three of the nine site-year environments for 'June Belle' and four of the site-year environments for 'Florida 2-14'. In those years, bolting seriously reduced 'June Belle' and 'Florida 2-14' yields; 'Florida Slobolt M68' yields ranged from at least two to 10 times more than those of the standard cultivars. Differential vernalization in the Everglades also contributed to inflated standard errors (which were about twice as large as those of 'Florida Slobolt M68') of the standard cultivars (Table 1). Similar to the standard cultivars, 'Florida Slobolt M68' is susceptible to blackheart caused by inadequate $\mathrm{Ca}$ levels, B-related transverse cracking in the nodal region, and longitudinal cracking. These disorders can be reduced with careful plant nutrition management. Compared to the standard cultivars, 'Florida Slobolt M68' has other similar horticultural qualities, including pithiness, brown stem, and petiole conformation.

\section{Availability}

'Florida Slobolt M68' is a public release from the Univ. of Florida. Breeders' seed was deposited with the Florida Foundation Seed Producers, Box 309, Greenwood, FL 32433, and stock seed with the Florida Celery Exchange. A commercial seed lot was sent to the USDA Germplasm Repository in Geneva, N.Y. For research purposes, small seed samples are available from B.S. or the USDA.

\section{Literature Cited}

U.S. Dept. of Agriculture. 1981. Objective description of variety: Celery [Apium graveolens $\mathrm{L}$. var. dulce (Miller) Pers.]. Exhibit C, form LMGS470-51 (8-81). U.S. Dept. of Agr., Beltsville, Md.

Wolf, E.A. 1958. 'Emerald': A new early blight resistant pascal celery. Florida Agr. Expt. Sta., Gainesville. Circ. S-109.

Wolf, E.A. 1970a. 'Earlibelle': A new early blight resistant celery. Florida Agr. Expt. Sta., Gainesville. Circ. S-207.

Wolf, E.A. 1970b. 'June Belle': A new early blight resistant celery for spring harvest in south Florida. Florida Agr. Expt. Sta., Gainesville. Circ. S208. 